\title{
Pengembangan Dewi Menari sebagai Desa Wisata Tanon Lereng Gunung Telomoyo di Kecamatan Getasan, Kabupaten Semarang
}

\author{
Djalal Fuadi ${ }^{1}$, Suharjo ${ }^{2}$, Koesoemo Ratih ${ }^{3}$, Ratnasari Diah Utami ${ }^{4}$, Dwi Sarbini ${ }^{5}$ \\ ${ }^{1,2,3,4}$ Fakultas Keguruan dan Ilmu Pendidikan, Universitas Muhammadiyah Surakarta, Indonesia \\ ${ }^{5}$ Fakultas Ilmu Kesehatan, Universitas Muhammadiyah Surakarta, Indonesia
}

\section{INFORMASI ARTIKEL}

Histori Artikel:

Submit: 28 Mei 2020

Revisi: 6 Juni 2020

Diterima: 28 Juni 2020

Publikasi: 2 Juli 2020

Periode Terbit: Juli 2020

\section{Kata Kunci: \\ desa mitra, \\ desa wisata menari, \\ olah kreatif, \\ keripik pegangan, \\ produk olahan, \\ penataan lingkungan}

Correspondent Author:

Djalal Fuadi

Fakultas Keguruan dan Ilmu Pendidikan

Universitas Muhammadiyah Surakarta,

Indonesia

Email: djalal.fuadi@ums.ac.id

\begin{abstract}
ABSTRAK
Dusun Tanon lereng gunung Telomoyo Kecamatan Getasan, kabupaten Semarang memiliki potensi Desa wisata (Dewi) menari yang dicanangkan sejak tahun 2012. Dewi yang menjadi salah satu destinasi wisata yang khas dan unik, dengan sajian paket hiburan menari oleh masyarakat dusun Tanon, disamping pagelaran seni, dolanan tradisional, wisata pembelajaran (outbond), wisata psikoterapi dll belum dikelola secara maksimal dan profesional. Seiring dengan perkembangan usaha paket wisata di desa menari Tanon, persoalan penataan lingkungan, pengembangan potensi untuk produksi industri kreatif, dan pengelolaan peternakan yang bersih perlu menjadi perhatian. Kegiatan Ipteks bagi Desa Mitra (IbDM) ini, difokuskan pada dua kegiatan. Pertama, bidang lingkungan dan kedua, kegiatan berbasis pada aspek ekonomi dalam mengangkat potensi tanaman lokal, yaitu pegagan dan sayur-sayuran. Pendampingan penataan lingkungan asri, pengelolaan peternakan bersih dan pengembangan usaha hasil pertanian berbasis potensi lokal, dapat menambah daya tarik dan kenyamanan pengunjung untuk menikmati suasana pedesaan, meningkatkan jumlah pengunjung, meningkatkan pendapatan masyarakat melalui pembelian produk-produk olahan kreatif dari masyarakat, yang muaranya adalah peningkatan kesejahteraan dan kualitas hidup masyarakat di desa wisata, serta terwujudnya pengelolaan dan pengembangan desa wisata yang lebih menarik dan kreatif, pengelolaan peternakan yang bersih, dikembangkan pertanian produktif serta diversifikasi aneka produk olahan berbasis potensi lokal.
\end{abstract}

\section{Pendahuluan}

Salah satu kabupaten di Jawa Tengah yang memiliki potensi wisata namun belum dikelola secara profesional dan maksimal adalah beberapa potensi wisata uniq yang tersebar di Kabupaten Semarang. Kabupaten Semarang merupakan wilayah daratan rendah dengan perbukitan dan pegunungan berada pada ketinggian rata-rata $636 \mathrm{~m}$ di atas permukaan air laut, dengan suhu berkisar antara 23o C - 26o C dan luas wilayah mencapai 95.020.675 Ha. Pegunungan yang banyak wilayah ini, seperti Gunung Ungaran, Gunung Merbabu, gunung Telomoyo, gunung Gajah Mungkur, Gunung Mergi serta perbukitan dan Rawapening merupakan sumber daya alami yang menunjang pertumbuhan kepariwisataan Kabupaten Semarang. Posisi Kabupaten Semarang sangat 
strategis sebagai daerah penyangga ibukota Provinsi Jawa Tengah yang memberikan peluang dan kesempatan untuk mengembangkan segala potensi yang di miliki khususnya bidang pariwisata. Kabupaten Semarang banyak memiliki potensi wisata yang dapat dikembangkan, menurut catatan ada sekitar 43 buah obyek wisata namun karenan adanya keterbatasan dalam pengelolaan baru beberapa obyek wisata yang dapat ditawarkan kepada wisatawan, antara lain, Agro Wisata Tlogo, Agro Wisata Banaran, Bukit Cinta, Wana Wisata Umbul Songo, Wana Wisata Penggaron, Air Terjun Semirang, Kartika Wisata Kopeng, Wisata Giri Gahana Sidomukti, Monumen Palagan Ambarawa, Museum KA Ambarawa, Candi Gedong Songo, Situs Brawijaya, Goa Maria Kerep, Curug 7 Bidadari Pemandian Muncul, Taman Wisata Rawa Permai, Kolam Renang Indah Sari, Kolam Renang Tirto Argo, Bandungan Indah.

Getasan adalah sebuah kecamatan di Kabupaten Semarang, Jawa Tengah, yang terletak di antara Kota Salatiga dan Kabupaten Magelang. Kecamatan ini terletak di lereng GunungMerbabu dan beberapa objek wisata andalannya adalah Desa Vokasi Kopeng, Pertapaan Bunda Pemersatu Gedono, dan Desa Menari Tanon. Dusun Tanon adalah salah satu dusun yang masuk dalam wilayah Desa Ngrawan Kecamatan Getasan Kabupaten Semarang Propinsi Jawa Tengah. Terletak di bawah kaki Gunung Telomoyo yang di huni oleh 37 kepala keluarga dan 157 jiwa menawarkan suasana alam pedesaan yang masih jauh dari kebisingan dan hiruk pikuk kehidupan sosial modern yang serba semrawut. Letak Desa Ngrawan tidak jauh dari pusat-pusat kota, misalnya dari Kota Magelang 33,3 Km, dari Jogjakarta 76,28 Km, dari Solo $50 \mathrm{Km}$, dari Semarang $58 \mathrm{Km}$, sedangkan dari Salatiga 11,7 Km. Sehingga dari sisi aksesibilitasnya mudah terjangkau, dan bisa ditempuh paling lama 2 jam dari Jogjakarta. Sebagai sebuah desa yang berada pada ketinggian, karena berada di lereng pegunungan Telomoyo, memilki hawa yang sangat sejuk, jauh dari polusi, dekat dengan pusat penghasil sayur mayur, memiliki potensi alam yang sangat menarik dan jauh dari kesemrawutan dan kebisingan. Ini menjadi salah satu magnit untuk datang ke desa menari tanon.

Potensi dan ketrampilan masyarakat dalam mengelola dan mengembangkan desa menari wisata Tanon Getasan, masih memiliki kendala dan permasalahan yaitu Jumlah kunjungan wisatawan ke desa wisata Tanon masih cukup terbatas, sebulan baru mencapai angka 300-400 pengunjung, hal ini disebabkan oleh promosi yang masih terbatas dan akses jalan yang sempit dan belum memadai. Penataan lingkungan desa wisata yang masih sederhana karena dilakukan secara swadaya belum dan belum ada pendampingan dari Perguruan tinggi maupun Pemerintah daerah kabupaten Semarang untuk menata lokasi desa wisata Tanon. Kreatifitas dan ketrampilan pengembangan usaha berbasis desa wisata dari masyarakat masih sangat rendah, masih berpusat pada figure personal, yaitu Kang Trisno yang menjadi pemuda pelopor di desa wisata Tanon Getasan. Potensi hasil pertanian dan peternakan lokal, belum dikembangkan dengan baik dan diolah menjadi produk olahan kreatif sehingga belum memberikan nilai tambah \& peningkatan pendatan bagi masyarakat.

Untuk menjawab permasalahan-permasalahan lingkungan dan pengembangan ekonomi yang dihadapi oleh mitra desa wisata Tanon Getasan, solusi yang ditawarkan pada kegiatan IbDM ini, meliputi : Bidang Lingkungan meliputi Penataan lingkungan jalan, rumah dan peternakan agar menjadi lebih bersih dan asri; Pengembangan peternakan bersih, dengan penanganan lingkungan akibat bau kotoran dan cemaran limbah dengan pemanfaatan instalasi biogas; Pemanfaatan kotoran ternak sebagai sumber energy rumah tangga yang murah dan produksi pupuk organic; Pengelolaan peternakan bersih dan pertanian organik, untuk mendukung penciptaan lingkungan yang bersih. Bidang Ekonomi, meliputi: Perbaikan kemasan dan perluasan jaringan pemasaran produk keripik pegagan oleh kelompok kewirausahaan Cinta Karya; Perbaikan kemasan dan perluasan jaringan pemasaran produk sabun susu melalui pembentukan kerjasama dan jaringan dengan pengelola desa wisata di kabupaten Semarang; Pendampingan kepada UMKM tentang manajemen usaha \& pembukuan yang tertib dan rapi; Pendampingan pemasaran online untuk perluasan pemasaran produk-produk dari mitra.

Hasil keseluruhan dan luaran yang diharapkan dari kegiatan IbDM ini adalah terwujudnya pengelolaan dan pengembangan desa wisata yang lebih menarik dan kreatif, pengelolaan peternakan yang 
bersih, dikembangkan pertanian produktif serta diversifikasi aneka produk olahan berbasis potensi lokal.

\section{Metode Pelaksanaan}

Program Ipteks bagi Desa Mitra (IbDM) ini mengunakan pendekatan RRA (Rapid Rural Appresial) /PRA (Partisipatori Rural Appresial). RRA dan PRA adalah falsafah, pendekatan metode yang dikenal sebagai memahami desa secara cepat. Adapun prinsip-prinsip pendekatan RRA dan PRA yang dipakai dalam kegiatan ini adalah : Belajar Secara Cepat dan Progresif, melalui eksplorasi yang terencana, pemakaian metode yang fleksibel, improvisasi, pengulangan serta menyesuaikan dengan proses belajar atau pemahaman. Optimalisasi Pertukaran, mengkaitkan biaya pemahaman dengan informasi yang benarbenar bermanfaat bagi masyarakat di dusun Tanon desa Ngrawan Kecamatan Getasan kabupaten Semarang, dengan pertukaran antar kuantitas, kegayutan, keakuratan serta ketepatan waktu. Pemberian fasilitas, artinya memberikan fasilitas penyelidikan, analisis, penyajian dan pemahaman oleh masyarakat di wilayah dusun Tanon-Ngrawan-Getasan, sehingga mereka dapat menyajikan dan memiliki hasilnya, dan juga mempelajarinya. Kesadaran dantanggung jawab diri yang kritis, artinya fasilitatorsecara terus-menerus menguji tingkah laku mereka dan mencoba melakukannya secara lebih baik. Saling berbagi informasi dan gagasan antar masyarakat di dusun Tanon desa Ngrawan Kecamatan Getasan dengan fasilitator, dan antar fasilitator yang berbeda, serta saling berbagi wilayah kegiatan, pelatihan dan pengalaman antar organisasi yang berbeda.

Kegiatan-kegiatan diatas dilakukan dengan Focus Group Discussion (FGD), pelatihan kepada warga, pendampingan dan diakhiri dengan evaluasi dan monitoring. Mengacu pada rencana pengembangan desa wisata Tanon oleh Kepala Desa Ngrawan yang menetapkan bahwa dusun Tanon sebagai kawasan pengembangan wisata, peternakan dan agropolitan dengan mempertimbangkan kesesuaian lahan, dan potensi tenaga kerja, maka kegiatan IbDM di dusun Tanon kecamatan Getasan Kabupaten Semarang adalah sebagai berikut: 1) Penataan lingkungan jalan, rumah dan peternakan agar menjadi lebih bersih dan asri dan membuat suasana lebih nyaman bagi para wisatawan yang berkunjung ke desa wisata Tanon
Getasan; 2) Pengembangan peternakan bersih, dengan penanganan lingkungan akibat bau kotoran dan cemaran limbah dengan pemanfaatan instalasi biogas sebagai sumber energy rumah tangga yang murah dan produksi pupuk organik. 3) Pemanfaatan pupuk hasil dari pengolahan kotoran ternak dan pengembangan tanaman pekarangan yang produktif seperti singkong super, jagung hibrida, Sengon dll. engembangan pertanian singkong super terpadu (dengan peternakan sapi atau kambing).

\section{Hasil Pelaksanaan dan Pembahasan}

Pengembangan potensi lokal dusun Tanon Getasan, meliputi: Perbaikan kemasan dan perluasan pemasaran produk keripik pegagan yang telah dihasilkan oleh Kelompok Kewirausahaan Cinta Karya dusun Tanon; Perbaikan kemasan dan perluasan pemasaran produk sabun susu dari Pokdarwis desa menari Tanon, sebagai salah satu souvenir dari dusun Tanon Getasan; Peningkatan nilai tambah dari sayursayuran, melalui aneka produk olahan tepung sayuran, seperti mie, nugget, greenis, dan biskuit.

Alasan pemilihan mitra desa wisata Tanon kecamatan Getasan Semarang sebagai mitra dalam kegiatan IbDM ini, karena 1) desa wisata menari ini telah menjadi salah satu desa/daerah binaan dari LPPM UMS selama waktu satu tahun (2015-2016), 2) walaupun masih sangat sederhana dan belum pernah mendapatkan bantuan dana dan pendampingan dari pemerintah kabupaten Semarang, tetapi telah menjadi salah satu tujuan wisata bagi para siswa, guru dan para orang tua. 3) dilaporkan dalam 3 tahun terakhir tercatat 3.000 pengunjung setiap tahunnya datang ke dusun Tanon Getasan. Dan lebih dari 40 orang warganya terlibat dalam Pokdarwis desa menari, baik sebagai penari, penjual aneka makanan dan kerajinan tangan, tim promosi, dan pendamping (guide) bagi wisatawan.

Beberapa kepakaran dan keahlian yang diperlukan dalam kegiatan IbDM ini adalah keahlian penataan lingkungan untuk mendukung dan memperbaiki tata ruang desa wisata, pengetahuan dan ketrampilan tentang pengolahan tepung sayuran, kesehatan lingkungan, peternakan organik \& terpadu, serta pengembangan usaha dan pemasaran.

Bersama-sama dengan masyarakat Dusun Tanon telah mendesain dan menata lingkungan, 
meliputi penataan jalan lingkungan desa, mengubah struktur jalan setapak menuju lokasi out bond dari trap tanah dan bambu menjadi batu dan semen agar diperoleh keamanan dan kenyamanan pejalan kaki. Pelibatan masyarakat merupakan salah satu aspek penting dalam pengembangan kawasan wisata (Pandit, 1999; Gede Pitana, 2005; Soemanto, 2016). Gambaran umum sarana pendukung di Dusun Tanon sebelum dilaksanakan pengabdian seperti tampak pada ilustrasi gambar 1 .

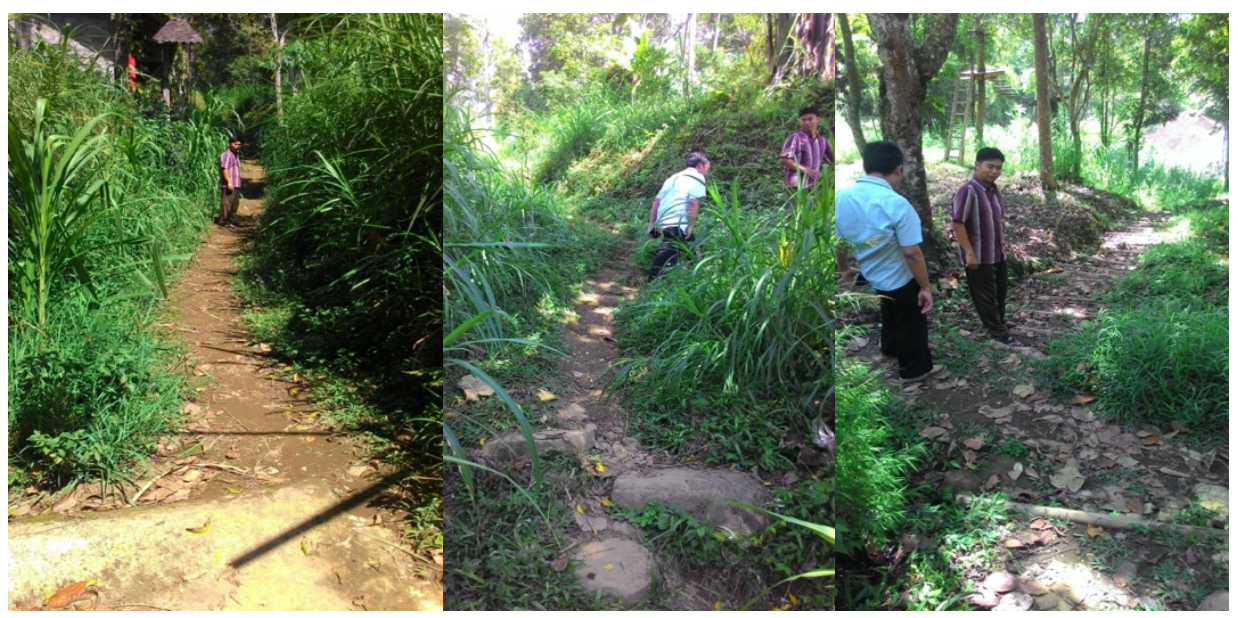

Gambar 1 Sebelum Dilakukan Penataan dan Pengerjaan Jalur Outbond

Berdasarkan gambar 1 tersebut tampak bahwa jalur ourbond yang sudah ada selama ini belum dikolola dengan prosfesional dan maksimal. Oleh sebab itu, supaya menjadi salah satu daya dorong maka diperlukan penataan dan pengerjaan ulang sebagaimana gambar 2 . Hasil pengembangannya diilustrasikan memalui gambar 3 .

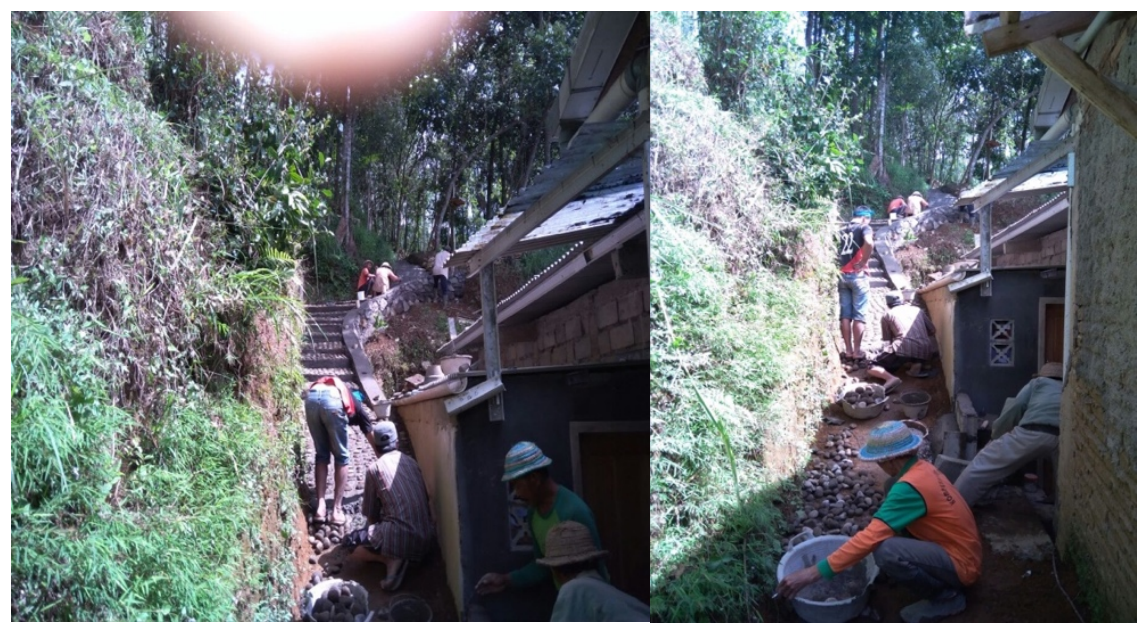

Gambar 2 Proses Rintisan dan Pengerjaan Jalan Setapak 


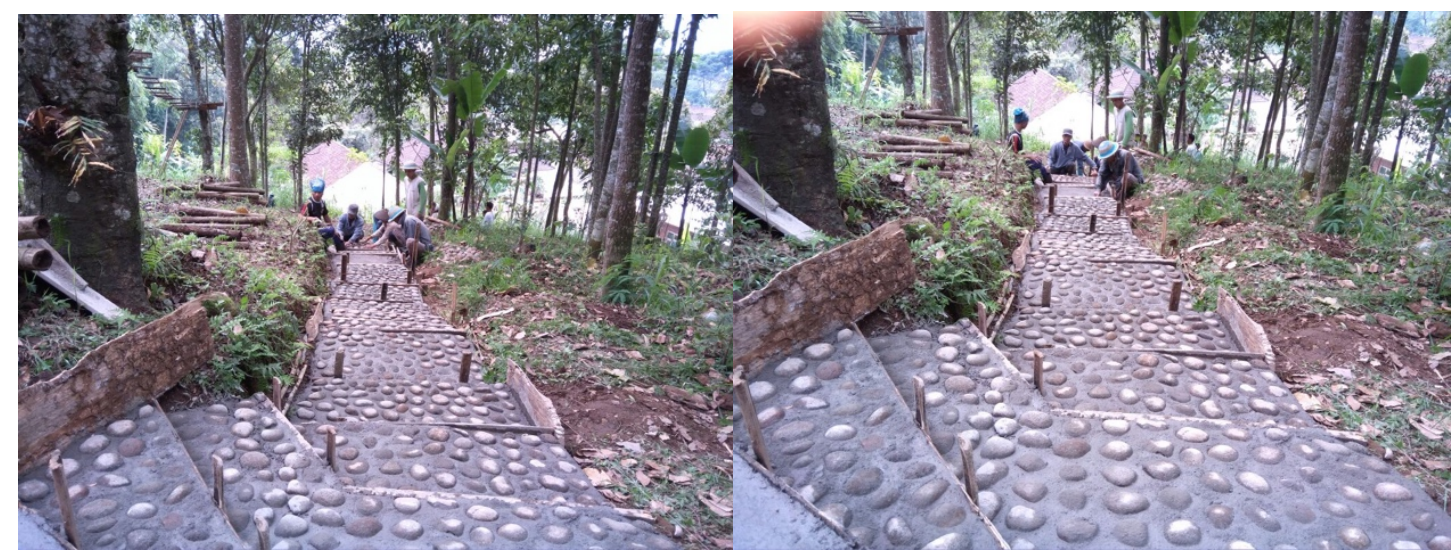

Gambar 3 Seteleh Pengerjaan Jalan Setapak Menuju Lokasi Outbond

Perancangan desain penataan jalan, pekarangan dan peternakan di lokasi desa wisata Tanon Getasan, serta penataan peternakan agar tercipta suasana yang lebih asri dan nyaman, serta lingkungan yang sehat, sehingga mendukung keindahan dan kenyamanan berkunjung di lokasi Desa Wisata Menari Tanon. Perancangan lokasi wisata merupakan pilar penting dalam mengembangkan suatu kawasan wisata (Pemayun, 2010; Nailu, 2012; Kastolani, 2016; Komajaya, 2013).

Pengembangan dan pemanfaatan peternakan bersih, melalui penanganan limbah ternak yang mengakibatkan lingkungan bau kotoran ternak dengan pemasangan Kubah Digester untuk instalasi biogas dan pengerjaan instalasi untuk pemanfaatan tenaga listrik. Ilustrasi teknologi selengkapnya pada Gambar 4 dan 5.
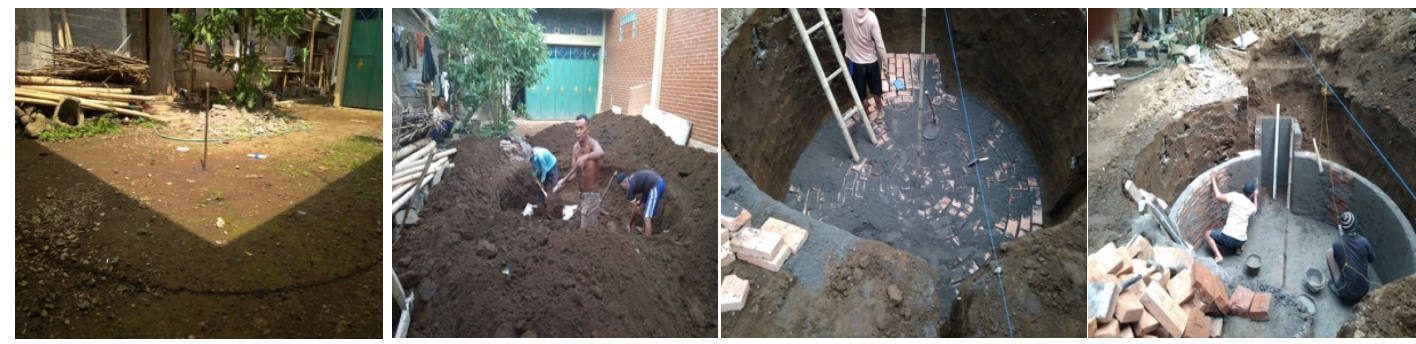

Gambar 4 Teknik Pengolahan Kotoran Ternak
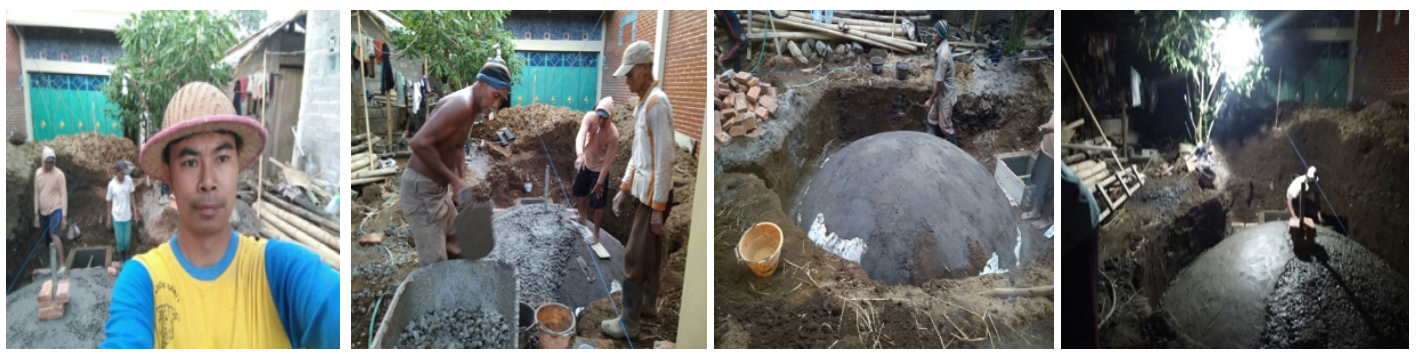

Gambar 5 Hasil Pengembangan Pengolahan Kotoran Ternak

Pemanfaatan kotoran ternak sebagai sumber energi rumah tangga yang ramah dan murah serta produksi pupuk organik. Melakukan pelatihan dan pendampingan kewirausahaan, manajemen, 
kelembagaan usaha olahan kreatif dan pembuatan/pebaikan kemasan terhadap produk makanan dan souvenir dari dusun Tanon Getasan. Pelatihan dan pengembangan kepada masyarakat sekitar perlu dilakukan secara terus-menurus untuk bisa mendongkrak daerah wisata (Eva, 2015; Binayew, 2016; Andika, 2015).
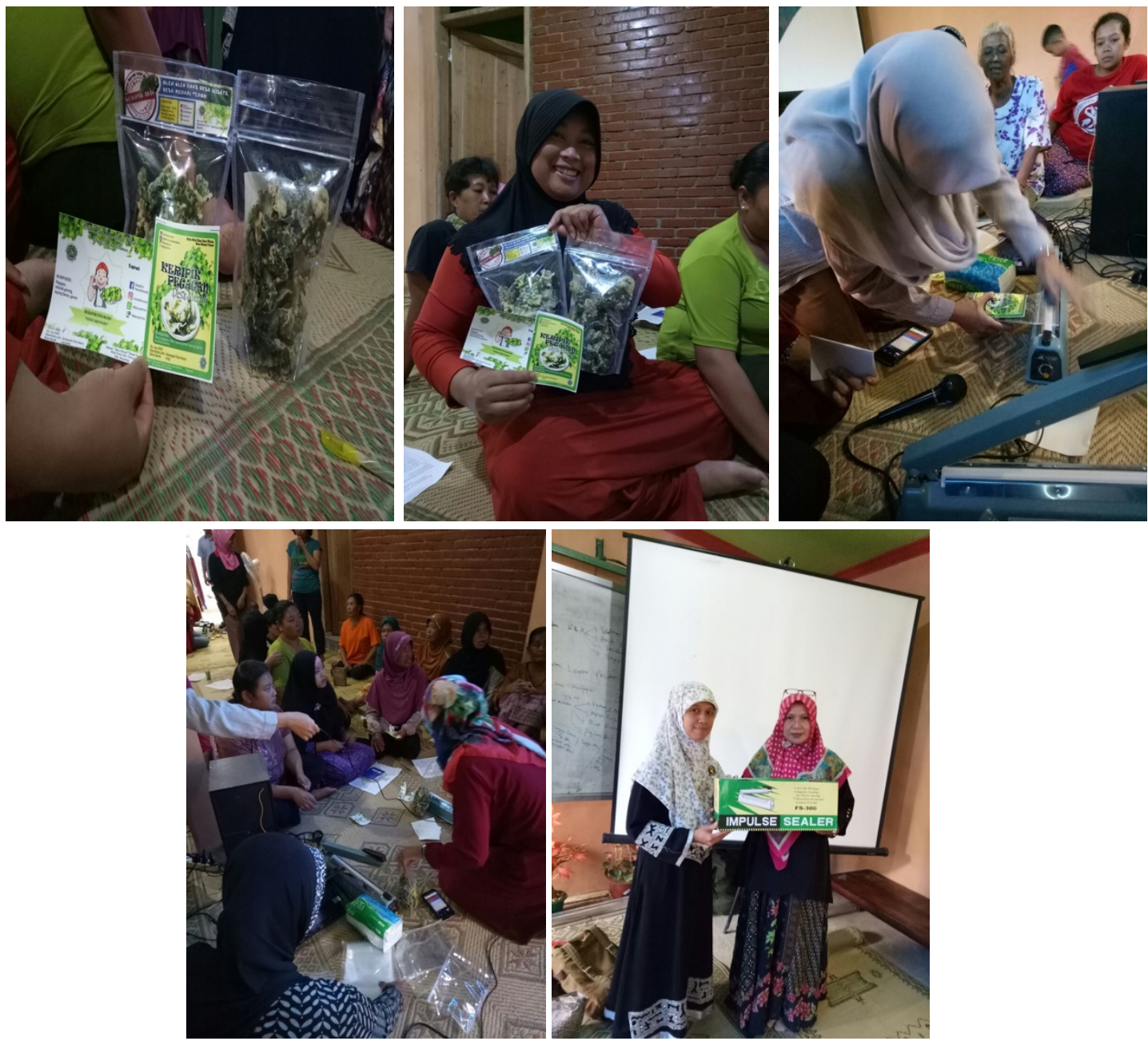

Gambar 6 Hasil Pengembangan Produk Olahan
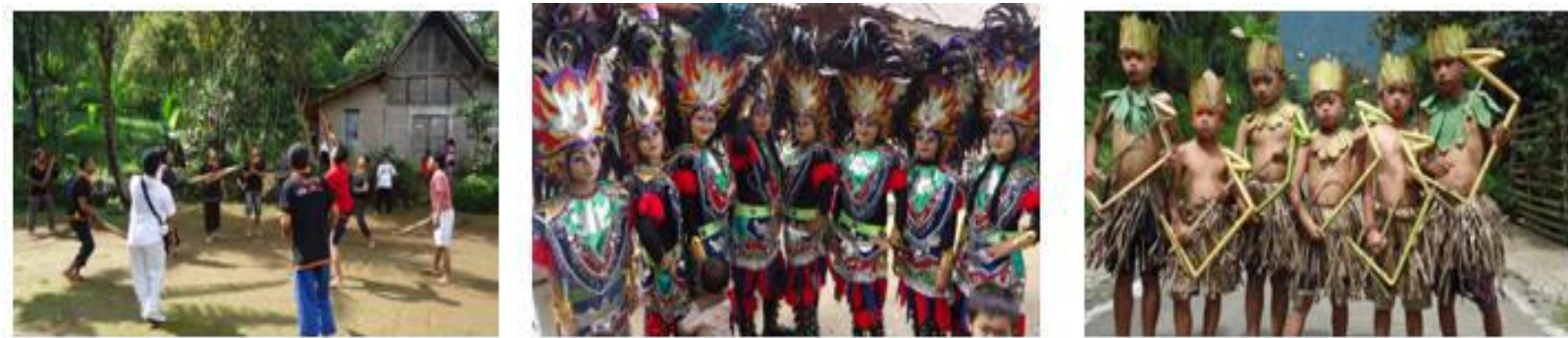

Gambar 7 Paket Hiburan Dolanan Tradisional dan Tari-tarian

Masyarakat dusun Tanon Getasan, hidup rukun dan masih memelihara budaya gotong royong. Masyarakat Tanon berkembang dalam rumpun keluarga dari keturunan Ki Tanuwijoyo yang sebagian besar masyarakatnya adalah petani dan peternak. Namun demikian, di Dusun Tanon Desa Ngrawan banyak menyimpan potensi yang jika dieksplorasi akan menjadi potensi yang bisa menjadi potensi kekayaan 
lokal terutama dalam menjaga tata cara tradisi leluhurnya. Menurut cerita tokoh masyarakat keturunan Ki Tanuwijoyo, dusun Tanon merupakan masyarakat yang gemar berkesenian, sejak era jayanya ketoprak klasik, mayoritas masyarakat dusun tanon terlibat baik sebagai pemain ketoprak maupun dalam kelompok karawitan. Seiring dengan kemajuan teknologi komunikasi, maka meredupnya kesenian ketoprak masyarakat dusun tanon dan menyerap kesenian tradisi lain. Melihat darah yang mengalir memiliki jiwa seni, maka akan menjadi pintu masuk yang sangat tepat untuk menggali kembali potensi kesenian yang ada dan terkelola dengan baik seperti kuda lumping dan topeng ireng, kuda debog, juga memiliki kuliner khas desa misal kripik daun pegagan, getuk coklat, sayur lodeh daun jipang, sambel korek versi tanon, dsb.

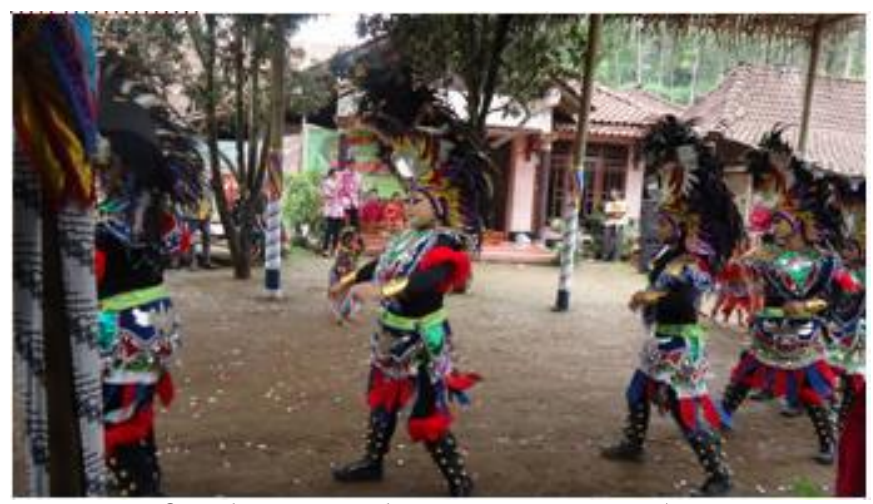

Gambar 8 Pagelaran Tari Topeng Ayu

Masalah yang dihadapi dalam pengembangan desa wisata Tanon adalah kondisi akses jalan masuk ke dusun Tanon, yang masih sempit, belum tersedia area parkir untuk kendaraan pengunjung, penataan lingkungan yang perlu perbaikan, kondisi peternakan sapi dan kambing yang dikelola secara konvensional dan belum memadukan dengan pertanian organik, lingkungan peternakan kotor dan bau, pengelolaan pertanian dan hasil pertanian yang belum dikembangkan untuk meningkatkan jumlah pendapatan petani.

Oleh karena itu, kegiatan pengabdian kepada masyarakat dilaksanakan melalui tahapan dan program Ipteks bagi Desa Mitra (IbDM), yaitu:

1. Pendampingan masyarakat untuk desain dan penataan lingkungan desa wisata Tanon, agar menunjang kenyamanan dan meningkatkan daya tarik pengunjung ke desa wisata Tanon.

2. Pendampingan pengelolaan peternakan bersih, dengan memanfaatkan instalasi biogas yang juga dapat dimanfaatkan untuk sumber energi rumah tangga yang murah, dan produksi pupuk organik yang dapat dimanfaatkan dalam kegiatan pertanian dan perkebunan.
3. Pengembangan produk-produk kreatif dari olahan pangan berbasis potensi lokal, untuk mendukung pengembangan desa wisata, Pendampingan pembuatan kemasan produk olahan pangan lokal dan pengembangan promosi serta perluasan jaringan pemasaran paket-paket kunjungan ke desa menari wisata Tanon, Peningkatan pendapatan masyarakat melalui penguatan program kampung ternak.

Pada prinsipnya semua daerah atau dusun memiliki potensi-potensi wisata kedaearahan yang bernilai uniq. Potensi-potensi wisata tersebut memerlukan tata kelola dan pengembangan yang profesional yang didasarkan pada potensi SDM di sekitarnya (Sastrayuda, 2010; Sandra, 2011; Rahim, 2012). Dalam pengelolaaan dan pengembangan itu diperlukan pertimbangan nilai ekonomi (Bungin, 2013), komunikasi (Bachtiar, 2016), dan keberlanjutan yang berkelanjutan (Demartoto, 2016; Shakoor, 2014). Aspekaspek ini penting karena hakikat pengembangan wisata adalah untuk meningkatkan nilai ekonomi masyarakat setempat (Ismail \& Buang, 2019). Hakikat pendidikan dan latihan suatu masyarakat adalah untuk memakmurkan dan memartabatkan kehidupan (Prayitno, et al., 2019). 


\section{Simpulan}

Kegiatan pengamdian masyarakat ini telah berhasil melaksanakan aktifitas secara bersama-sama dengan masyarakat Dusun Tanon mendesain dan menata lingkungan, membangun secara gotong royong jalan setapak menuju lokasi out bond, penataan peternakan sehingga tercipta suasana yang lebih asri dan nyaman, dan diharapkan mendukung terciptanya keindahan dan kenyamanan berkunjung di lokasi desa wisata menari tanon. Penataan dan pengembangan peternakan sapi warga yang cukup menjanjikan, karena potensi pakan yang melimpah di sekitar usun Tanon.

Program Pengembangan peternakan bersih, melalui penanganan lingkungan akibat bau kotoran ternak dengan instalasi biogas dan untuk pemanfaatan tenaga listrik dapat terlaksana, meskipun mengalami perubahan lokasi titik penempatan kubah digester dari rencana semula, tetapi dengan perubahan ini justru akan memberikan pemanfaatan yang lebih luas. Pemanfaatan kotoran ternak sebagai sumber energi rumah tangga yang ramah dan murah sudah dapat dimanfaatkan oleh sebagian besar warga, produksi pupuk organik juga sudah dapat dimanfaatkan oleh sebagian warga desa. Penanganan peternakan yang bersih untuk mendukung penciptaan lingkungan yang bersih, sudah dapat ditangani dan dapat mengurangi bau kotoran ternak disekitar lingkungan desa.

Pendampingan untuk desain dan penataan lingkungan sebaiknya dilakukan secara terus menerus dan terkontrol, karena dengan kehadiran wisatawan dapat memberikan dampak negatif terhadap lingkungan desa, misal membuang sampah disembarang tempat oleh wisatawan bisa menjadikan persoalan tersendiri bagi warga, sehingga pemahaman masyarakat terhadap penanganan sampah yang mengganggu lingkungan perlu disosialisasikan, masalah yang lain adalah masyarakat belum bisa secara mandiri menjaga secara penuh hasil penataan lingkungan.

Hasil dari pembuatan instalasi biogas sebaiknya juga ada pendampingan secara berkelanjutan karena berkaitan dengan perawatan, keamanan dan keberlanjutan pemanfaatan instalasi biogas, karena instalasi ini memiliki keterkaitan dengan instalasi lain yaitu pemanfaatan kotoran ternak sebagai sumber energi. Jika tidak didampingi bisa jadi peralatan tidak bisa dimanfaatkan secara maksimal dan digunakan secara terus menerus.

\section{Daftar Pustaka}

Andika, G Very. 2015. Skripsi : "Strategi Pengembangan Obyek Wisata Umbul Ponggok sebagai Daya Tarik Wisata di Desa Ponggol Kecamatan Polanharjo Kabupaten Klaten Jawa Tengah".

Binayew Tamrat Getahun dan Yiheyis Argeu Yeshanew. 2016. "Sustainable Ecotourism Potentials and It's Challenges in Ethiophia: The Awash National Park in Focus". International Journal of Humanities and Social Science Research. Volume 2; Issue 4; April 2016; Page No.41-49.

Bungin, Burhan. 2013. Metodologi Penelitian Sosial dan Ekonomi. Jakarta : Kencana Prenada Media.

Demartoto, Argyo. 2014. Habitus Pengembangan Pariwisata Konsep dan Aplikasi. Surakarta: UNS Press.

Eva Rachmawati, Harini Muntasib dan Arzyana Sunkar. 2015. "Interaksi Sosial Masyarakat dalam Pengembangan Wisata Alam di Kawasan Gunung Salak Endah". Bachtiar, Wardi. 2006. Sosiologi Klasik : Dari Comte Hingga Parsons. Bandung: PT. Remaja Rosdakarya.

Gede Pitana. dan Ir. Putu G. Gayatri M.Di. 2005. Sosiologi Pariwisata. Yogyakarta : ANDI.

Ismail, A. S., \& Buang, N. A. (2019). Development of Entrepreneurship Intentions among School Students in Malaysia. Indonesian Journal on Learning and Advanced Education (IJOLAE), $1(1), 48-53$.

Kastolani, Wanjat. 2016. "Hubungan Daya Tarik Wisata dengan Motivasi Berkunjung Wisatawan ke Alam Wisata Cimahi". Jurnal Manajemen Resort dan Leisure, Vol.13, No.1, April 2016.

Mueller, J. G., Assanou, I. H. B., Dan Guimbo, I. R. O., \& Almedom, A. M. (2010). Evaluating rapid participatory rural appraisal as an assessment of ethnoecological knowledge and local biodiversity patterns. Conservation Biology, 24(1), 140-150.

Nailu,Rahman. 2012. "Perspektif Stakeholders terhadap Potensi Obyek dan Daya Tarik Wisata (ODTW) Telaga Ngebel Kabupaten Ponorogo" Jurnal 
Bumi Indonesia Volume 1, Nomor 1, Tahun 2012.

Pemayun, Anom. 2010. Format Kerjasama Pengelolaan Daya Tarik Wisata Antara Pemerintah Kabupaten Gianyar dengan Desa Pakraman. Jurnal Analisis Pariwisata Volume 10 Nomor 1, Juli 2010 : 9 - 108, hal 9- 15.

Pendit, Nyoman S. 1999. Ilmu Pariwisata Sebuah Pengantar Perdana. Jakarta: Pradnya Paramitha.

Prayitno, H. J., Kusmanto, H., Nasucha, Y., Rahmawati, L. E., Jamaluddin, N., Samsuddin, S., \& Ilma, A. A. (2019). The Politeness Comments on The Indonesian President Jokowi Instagram Official Account Viewed From Politico Pragmatics and The Character Education Orientation in The Disruption Era. Indonesian Journal on Learning and Advanced Education (IJOLAE), $1(2), 52-71$.

Rahim, Firmansyah. 2012. Pedoman Kelompok Sadar Wisata: Direktur Jenderal Pengembangan
Destinasi Pariwisata Kementrian Pariwisata dan Ekonomi Kreatif.

Republik Indonesia. 2009. Undang-Undang No. 32 Tahun 2009 tentang Perlindungan dan Pengelolaan Lingkungan Hidup. Lembaran Negara RI, No. 5059. Sekretariat Negara. Jakarta.

Sandra Sanchez. 2011. Community - Based Tourism In Developing Countries : A Case Study". Journal of Tourism. Vol. 6, No. 1, Th 2011, pp. 69-84.

Sastrayuda, Gumelar. 2010. Handout Mata Kuliah Concept Resort and Leisure: "Strategi Pengembangan dan Pengelolaan Resort and Leisure".

Shakoor, Ali. 2014. "A Perspective on the Role of Tourism in Determining Evaluation and Monitoring Patterns in Darab Rural Development" . European Online Journal of Natural and Social Sciences Tahun 2014 vol.3, No.2, pp.326-330 ISSN 1805-3602.

Soemanto, RB. 2010. Sosiologi Pariwisata. Jakarta : Universitas Jakarta. 